\title{
Hibernoma de mano - reporte de un caso
}

\section{Hibernoma of the Hand-Case Report}

\author{
Lucia d'Oliveira ${ }^{1}$ Matias Craviotto ${ }^{1}$ Daniel Wolff $^{1}$ \\ ${ }^{1}$ Hospital Militar Central, Montevideo, Montevideo, Uruguay \\ Address for correspondence Lucia d'Oliveira, MD, Hospital Militar \\ Central, Montevideo, Montevideo, Uruguay \\ Rev Iberam Cir Mano \\ (e-mail: dradoliveirapazos@gmail.com).
}

\section{Resumen \\ Palabras clave \\ - hibernoma \\ - tumores de la mano \\ - tumores lipomatosos}

Los lipomas son infrecuentes en la mano y representan aproximadamente el $1 \%$ de los tumores. Los hibernomas son tumores benignos lipomatosos raros, compuestos al menos en parte por células de grasa parda con citoplasma granular multivacuolado. El estudio por RMN es de gran utilidad, actualmente imprescindible. En la resonancia magnética se observan como una masa heterogénea. La presencia de células inmaduras multivacuoladas en la microscopia, confirman el diagnóstico de hibernoma. El tratamiento quirúrgico es de elección.

Lipomas are not frequent in the hand and represent approximately $1 \%$ of tumors. Hibernomas are rare benign lipomatous tumors, composed at least in part of brown fat cells with multivalued granular cytoplasm. The study by nuclear magnetic resonance (NMR) is very useful, currently essential. In NMR they are observed as a heterogeneous mass. The presence of immature multivacuolated cells in the microscopy confirm the diagnosis of hibernoma. Surgical treatment is of choice.

\section{Introducción}

Pocos casos han sido publicados en la literatura sobre hibernomas en la mano. ${ }^{1}$ Son tumores lipomatosos raros compuestos por grasa parda con citoplasma granular, multivacuolado. Pueden presentar dentro del mismo tumor sectores de tejido adiposo. ${ }^{2}$

El objetivo de este trabajo es presentar el caso clínico de un paciente con un hibernoma de palma de mano y discutir la presentación clínica, estudio de imagen, tratamiento quirúrgico y manejo postoperatorio. Se trata de un caso clínico interesante por su baja frecuencia y diagnóstico diferencial con tumoraciones malignas.

\section{Caso Clínico}

Varón de 51 años, periodista, zurdo. Presentaba una tumoración en la palma de la mano izquierda de dos años de evolución. Refería crecimiento progresivo, con una cierta alteración funcional dado el tamaño de la tumoración. No tenía dolor ni parestesias. Al examen presentaba una tumoración en la palma de la mano izquierda, principalmente sobre eminencia tenar ( - Fig. 1 ) de $7 \mathrm{~cm}$, redondeada, sin cambios en la piel que la recubría. De consistencia blanda, no dolorosa a la palpación, que no impresionaba estar en relación con los músculos tenares.

La ecografía informaba la presencia de una imagen isoecogénica heterogénea de límites poco netos.

La resonancia magnética mostraba una masa de $67 \mathrm{~mm}$ en corte coronal, $61 \mathrm{~mm}$ en corte transversal y $33 \mathrm{~mm}$ en el anteroposterior. En la región palmar media y tenar, era isointensa con respecto a la grasa subcutánea en secuencia ponderada en T1 e hiperintensa en STIR, de forma lobulada, con límites netos. Desplazaba los paquetes vásculo nerviosos digitales del pulgar e índice. Contactaba y desplazaba en sentido anterior el retináculo flexor y el nervio mediano sin infiltración de dichas estructuras. El informe concluía que la tumoración presentaba las características de un lipoma típico (-Fig. 2).

Bajo anestesia general y bajo campo exangüe se realizó el abordaje en la palma de la mano sobre eminencia tenar received

June 13, 2017

accepted

March 11, 2019
DOI https://doi.org/

10.1055/s-0039-1685521. ISSN 1698-8396.
Copyright $\odot$ Thieme Revinter

Publicações Ltda, Rio de Janeiro, Brazil
License terms

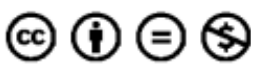




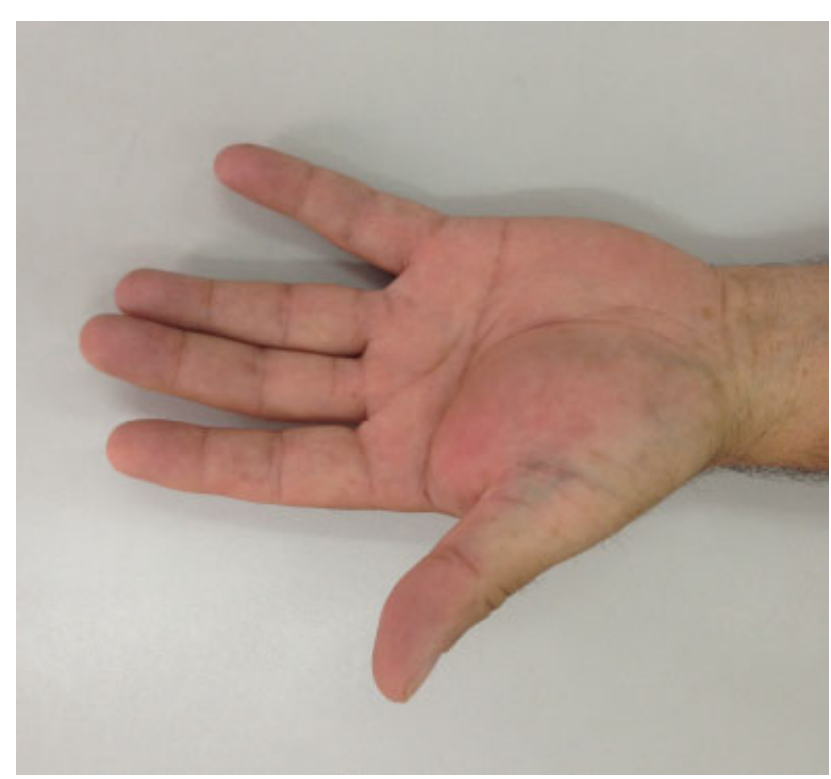

Fig. 1 Aspecto clínico de la mano con la tumoración de eminencia tenar.

principalmente. Se identificó una tumoración de coloración no homogénea con áreas amarillas y marrones, multilobulada, con plano de disección entre la piel y la misma. Se identificaron los nervios digitales y colaterales incluidos en la tumoración pero no infiltrados por la misma. Se extrajo la totalidad del tumor y se envió a estudio anatomopatológico (-Fig. 3). Se realizó hemostasia y cierre con apósito atado según la técnica de Brown.

El informe anatomopatológico informó en la macroscopía dos fragmentos amarillentos de $80 \times 30 \times 20 \mathrm{~mm}$ y de $40 \times 30 \times 20 \mathrm{~mm}$, parcialmente recubiertos por cápsula que al corte presentaba áreas parduzcas y rosadas. En la microscopía, se informó como una proliferación mesenquimática constituida por células adiposas multivacuoladas y células adiposas maduras, parcialmente recubierto por una cápsula de tejido conjuntivo con lo cual concluye como Hibernoma de mano (-Fig. 4).

Se realizó un seguimiento de 3 años no observándose recidiva del tumor. Así mismo, no presentó déficit motor o sensitivo, mejorando la molestia que motivó la consulta.

\section{Discusión}

El comité de la Organización Mundial de la Salud determinó nueve subtipos de tumores lipomatosos en la Clasificación de Tumores de Partes Blandas. Dentro de la clasificación se encuentra: lipoma, lipomatosis, lipomatosis del nervio, lipoblastoma, angiolipoma, miolipoma de partes blandas, lipoma cartilaginoso, lipoma a células de spindle/lipoma pleomórfico e hibernoma. ${ }^{2}$ Los hibernomas son tumores benignos lipomatosos raros, compuestos al menos en parte por células de grasa parda con citoplasma granular multivacuolado. La grasa parda se encuentra en los fetos de los mamíferos y desaparece en aquellas especies que no hibernan. La coloración oscura se debe a la alta proporción de mitocondrias en comparación con el tejido adiposo blanco. Su principal función es la producción de calor. En humanos se encuentra durante la vida intrauterina en cuello, axila, mediastino, sector peri aórtico y peri renales. En adultos se puede encontrar este tejido a modo de persistencias en las mismas topografías previamente mencionadas.

Existen publicaciones de topografías poco frecuentes de esos tumores. Solo encontramos una publicación de un hibernoma en mano. ${ }^{1}$ La presencia de hibernomas en cuero cabelludo, intracraneales, pared abdominal, hueco

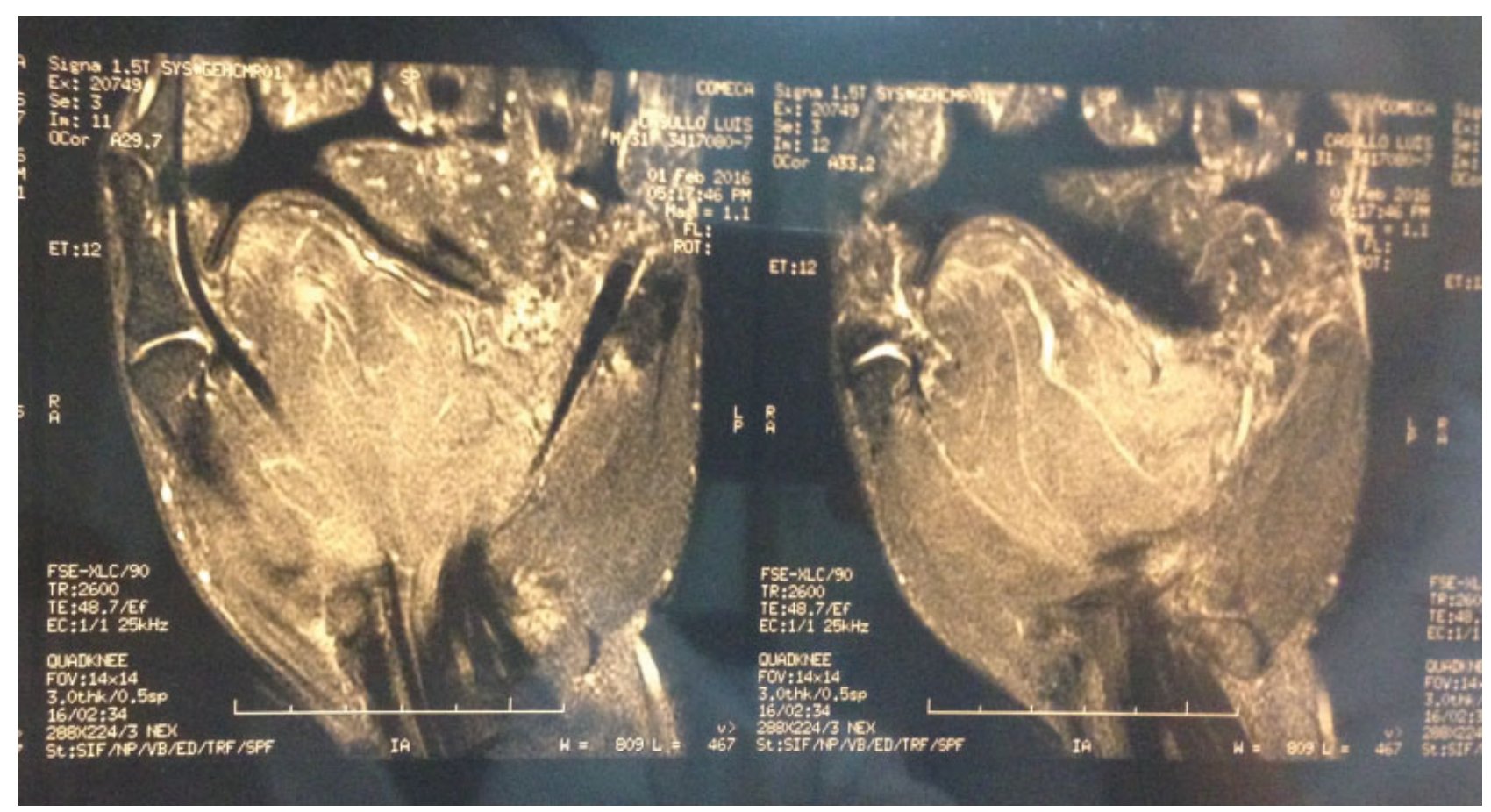

Fig. 2 Resonancia magnética. Tumoración isointensa con respecto a la grasa subcutánea en secuencia ponderada en T1 e hiperintensa en STIR, de forma lobulada, con límites netos. 


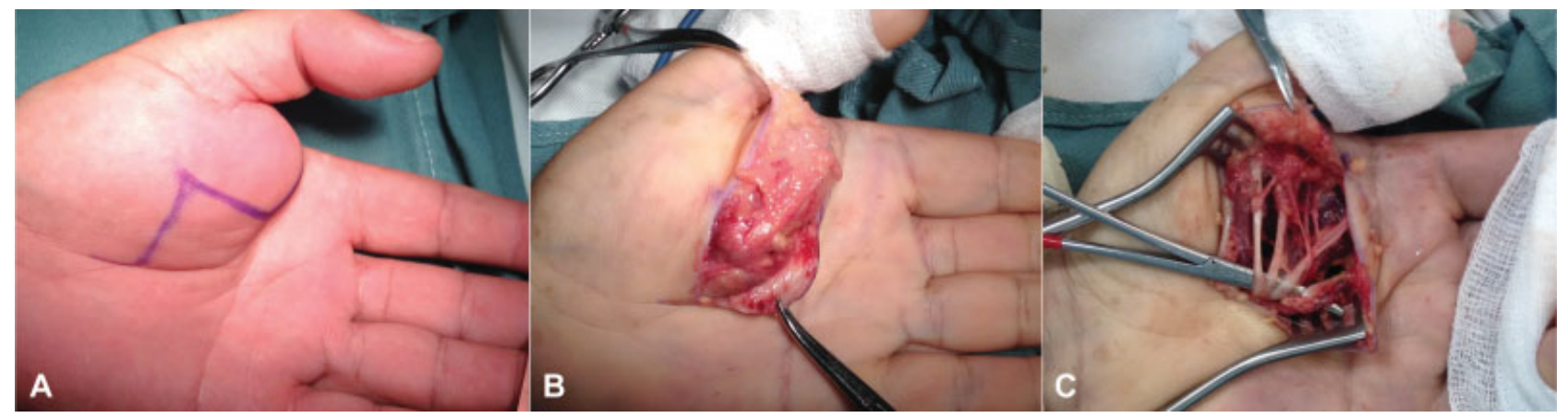

Fig. 3 Imágenes intraoperatorias de la biopsia excisional. A. Vía de abordaje. B. Tumoración de coloración no homogénea con áreas amarillas y marrones. C. Integridad de los paquetes vasculonerviosos tras la exéresis.

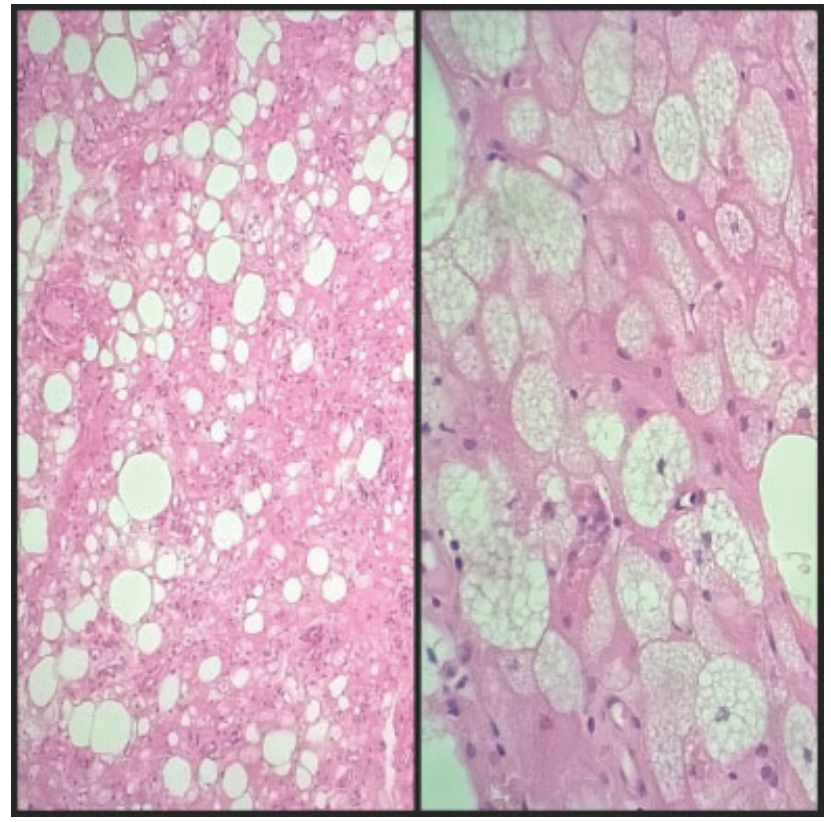

Fig. 4 Imagen microscópica: A izquierda a menor aumento, la diferencia de los adipocitos de la grasa parda y la grasa madura de mayor tamaño. A derecha, células adiposas pardas multivacuoladas en su citoplasma.

poplíteo, glúteo, escroto y región peri uretral, están descritas en la bibliografía como topografías inusuales. No queda establecida una predilección por sexo y su mayor pico de aparición es en la tercera década.

La presentación clínica puede variar en función de la topografía. Con mayor frecuencia se presenta como una tumoración asintomática, de la misma forma que ocurre con los lipomas. El paciente identifica una masa de crecimiento lento y progresivo, indolora, blanda, que no se adhiere a los planos profundos ni a la piel. En aquellos tumores que se presentan alejados de la superficie, el diagnóstico suele ser incidental. La aparición de síntomas se relaciona con la compresión de estructuras adyacentes.

El estudio de imagen puede evidenciar falta de homogeneidad que hace imprescindible el diagnóstico anatomopatológico para descartar la malignidad de la tumoración, si bien en nuestro caso, la resonancia magnética informó la tumoración como un lipoma típico.
La presencia de septos y tabiques en ocasiones son indistinguibles de los liposarcomas bien diferenciados. ${ }^{3}$ Dentro de los diagnósticos diferenciales de tumoraciones malignas la bibliografía menciona al liposarcoma, sarcoma a células claras y al sarcoma alveolar de partes blandas. ${ }^{3}$

Debido a la hipervascularización de esos tumores, no se recomienda la realización de biopsias mediante punción con aguja. ${ }^{4}$ Hay publicaciones de complicación con sangrado tras ese procedimiento, aunque también hay trabajos donde se realiza la biopsia con aguja sin complicaciones. ${ }^{3}$

A pesar de sus características macroscópicas atípicas con discromía, presentando colores que pueden ser sugestivos de malignidad como el amarillo parduzco, rosado y gris, esos tumores clásicamente no invaden estructuras vecinas aunque las envuelvan, como es el caso de nuestro paciente.

La confirmación diagnóstica se realiza por estudio anatomopatológico de la tumoración. Una proliferación mesenquimática constituida por células multivacuoladas y células adiposas maduras, acompañadas de un estroma adiposo, confirman el diagnóstico de hibernoma.

Como conclusión, debemos mencionar que la aparición de un hibernoma en la mano es infrecuente. Tanto la alteración funcional como las características de las pruebas de imagen, sugieren la realización de cirugía para la resección de la tumoración y posterior estudio anatomopatológico. De esa manera, se descarta la malignidad de la tumoración y se mejora la función de la mano del paciente.

Conflictos de interés

Ninguno.

\section{Bibliografía}

1 Cipriano CA, Gray RRL, Fernandez JJ. Hibernomas of the upper extremity: a case report and literature review. Hand (N Y) 2015; 10(03):547-549. Doi: 10.1007/s11552-014-9726-7

2 Fletcher CDM, Bridge JA, Hogendoorn PCW. WHO Classification of Tumors of Soft Tissue and Bone. 4th ed. Lyon: IARC Press; 2013

3 Dursun M, Agayev A, Bakir B, et al. CT and MR characteristics of hibernoma: six cases. Clin Imaging 2008;32(01):42-47

4 Kallas KM, Vaughan L, Haghighi P, Resnick D. Hibernoma of the left axilla; a case report and review of MR imaging. Skeletal Radiol 2003;32(05):290-294 